Review Article

\title{
Efficacy Comparison of Intravitreal Anti-VEGF Therapy for Three Subtypes of Neovascular Age-Related Macular Degeneration: A Systematic Review and Meta-Analysis
}

\author{
Jianqing Li $(\mathbb{D}$, Jiayi Xu, Yiyi Chen, Jiaju Zhang, Yihong Cao, and Peirong Lu (D) \\ Department of Ophthalmology, The First Affiliated Hospital of Soochow University, 188 Shizi Street, Suzhou 215006, China \\ Correspondence should be addressed to Peirong Lu; lupeirong@suda.edu.cn
}

Received 24 May 2018; Revised 24 August 2018; Accepted 16 September 2018; Published 23 October 2018

Academic Editor: Pierluigi Iacono

Copyright (c) 2018 Jianqing Li et al. This is an open access article distributed under the Creative Commons Attribution License, which permits unrestricted use, distribution, and reproduction in any medium, provided the original work is properly cited.

\begin{abstract}
Purpose. Intravitreal antivascular endothelial growth factor (anti-VEGF) therapy has been widely used for the treatment of neovascularization (NV) secondary to age-related macular degeneration (AMD). This study aimed to compare the efficacy among different subtypes of neovascular age-related macular degeneration (nAMD). Methods. PubMed, Embase, and the Cochrane Library were searched for eligible studies. We performed meta-analysis using Review Manager 5.3 and Stata/SE 12.0. Results. A total of 24 studies met our inclusion criteria and were included in the systematic review. At 3 months, the mean logarithm of the minimum angle of resolution ( $\log$ MAR) improvements were $-0.09,-0.18$, and -0.23 for type 1,2 , and 3 , respectively, while the mean macular thickness (MT) changes were $-104.83,-130.76$, and $-196.29 \mu \mathrm{m}$. At 12 months, the mean changes in Early Treatment of Diabetic Retinopathy Study (ETDRS) letters were 6.38, 8.12, and 9.37, while the MT decrease was 126.51, 126.52, and $139.85 \mu \mathrm{m}$, respectively. However, statistically significant difference was only found between type 1 and 3 in vision improvement, both in the short term $(p=0.0002)$ and long term $(p=0.01)$. Conclusions. The reactivity to VEGF inhibitors varied among different subtypes of nAMD. The efficacy of intravitreal anti-VEGF therapy in type 3 nAMD was statistically better than type 1 when considering vision improvement at 3 and 12 months. Thus, the lesion subtype is a predictor for the treatment outcome which can help guide prognosis.
\end{abstract}

\section{Introduction}

Age-related macular degeneration (AMD) is a progressive chronic disease of the central retina and a leading cause of vision loss worldwide [1] which basically has two types: exudative, neovascular, or wet AMD and nonexudative or dry AMD [2]. Neovascular age-related macular degeneration (nAMD), characterized by aberrant angiogenesis originating from the choroidal or, less frequently, the retinal circulation [3], is responsible for nearly $90 \%$ of the severe central visual acuity loss associated with AMD despite its lower incidence compared with the dry form [4].

The classification of nAMD was first developed in 1991 [5], which was based on fluorescein angiography (FA) and characterized lesion as "classic" or well-defined choroidal neovascularization (CNV) and "occult" or poorly defined CNV. A histologic classification proposed by Gass in 1994 [6] contained two different types: type 1 (located beneath the retinal pigment epithelium (RPE)) and type 2 (present beneath the sensory retina). Additional subtypes of nAMD, such as polypoidal choroidal vasculopathy (PCV) and retinal angiomatous proliferation (RAP), were further detailed with the development of optical coherence tomography (OCT). With advancements in imaging, a new anatomic classification based on FA and OCT was proposed [7], categorizing lesions as type 1 (sub-RPE), type 2 (subretinal), type 3 (intraretinal), or mixed neovascularization (NV). PCV was considered to be a special form of type 1 nAMD [7], while occult, classic, and RAP corresponded to type 1,2, and 3, respectively, [8] in our meta-analysis.

Intravitreal antivascular endothelial growth factor (antiVEGF) therapy has been identified to possess the potential to stabilize or even improve visual acuity in nAMD by clinical trials [9]. Several articles have studied the efficacy of antiVEGF on different subtypes of nAMD [10-12]; however, there has been no meta-analysis focusing on the efficacy 


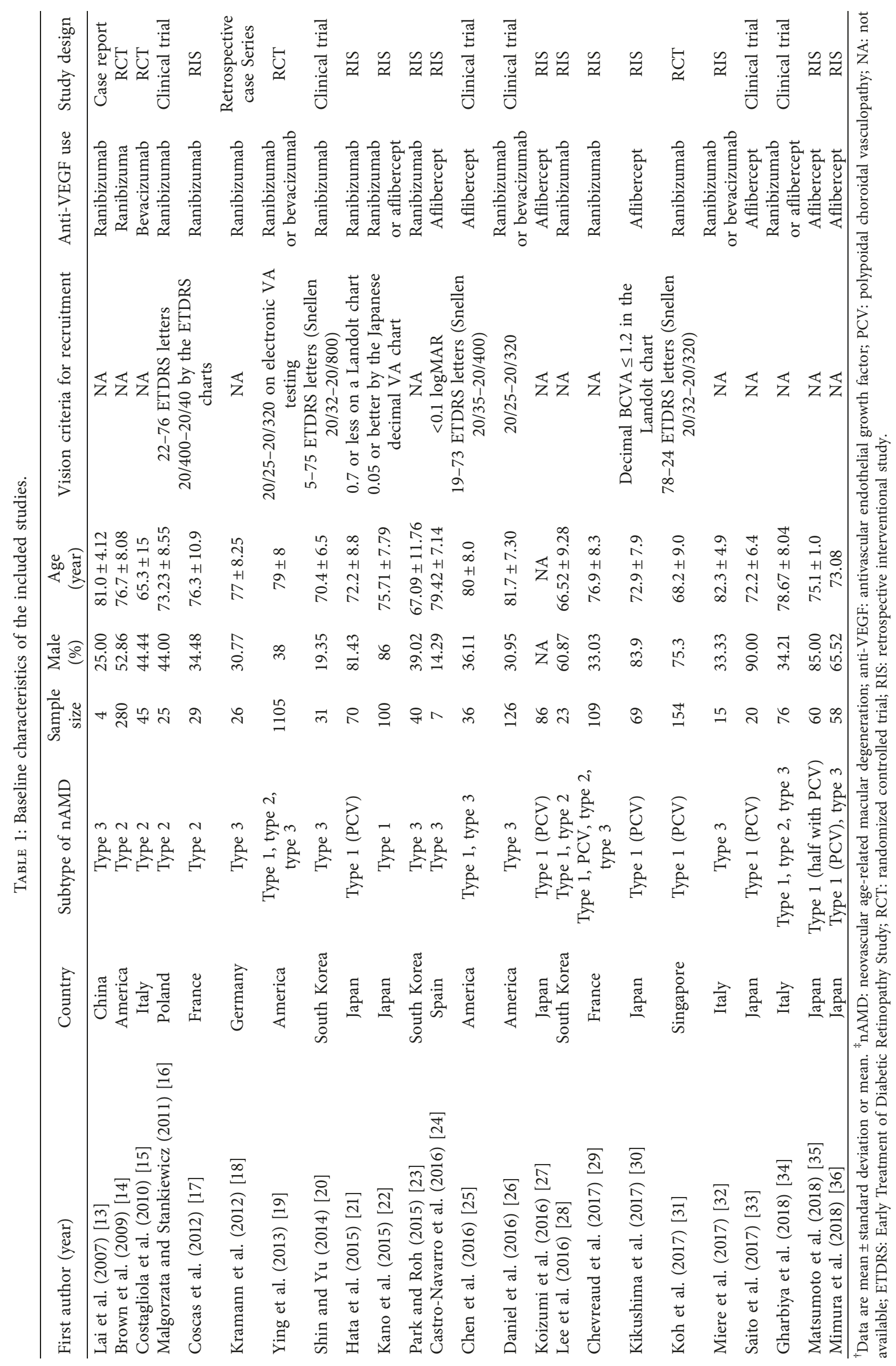




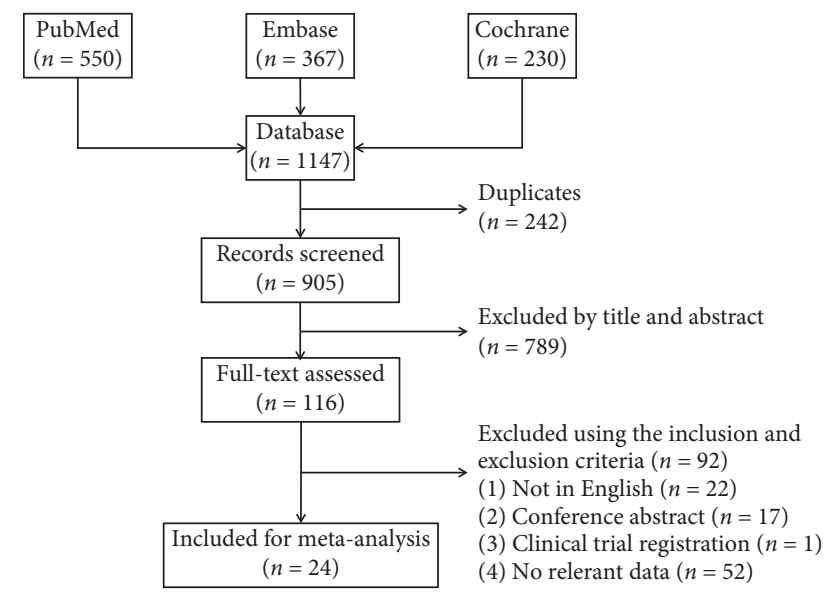

FIGURE 1: Flow diagram of the inclusion of studies in this metaanalysis.

comparison among all three types of nAMD. Therefore, we carried out a systematic review and meta-analysis in order to study the relationship between treatment efficacy and lesion subtype.

\section{Materials and Methods}

2.1. Search Strategy. Two independent reviewers (J. Li and J. $\mathrm{Xu}$ ) performed a systematic search in PubMed, Embase, and the Cochrane Library on March 16, 2018, for articles focusing on the efficacy of intravitreal anti-VEGF on different subtypes of nAMD. The search strategy was [("nAMD" AND "subtype") AND "anti-VEGF"] using the MeSH or Emtree terms as well as free words. Here, "nAMD," "wet AMD," and "exudative AMD" were searched for "nAMD"; "Type 1," "PCV," “occult," "poorly-defined," "sub-RPE," “Type 2," "classic," "well-defined," "subretinal," “Type 3," "RAP," and "intraretinal" were for different subtypes of nAMD, while "pegaptanib," "bevacizumab," "ranibizumab," "aflibercept" and "conbercept" were searched for "anti-VEGF."

2.2. Selection Criteria. The eligibility criteria were as follows: (1) any subtype of nAMD, (2) treatment-naive nAMD, (3) anti-VEGF monotherapy, (4) efficacy measured by vision improvement or macular thickness (MT) changes, and (5) efficacy measured at 3 months or 12 months. Those studies which were not in English with no full text or irrelevant data were excluded. Any disagreements about the inclusion of an article for full review were resolved by a third researcher (P. Lu).

2.3. Assessment of Risk of Bias. "Risk of bias" of each included article was assessed using "risk of bias table," which was suitable for both randomized and nonrandomized studies, according to the Cochrane Handbook for Systematic Reviews of Interventions Version 5.1.

2.4. Data Extraction. The characteristics extracted from the eligible articles included the first author's name, publication

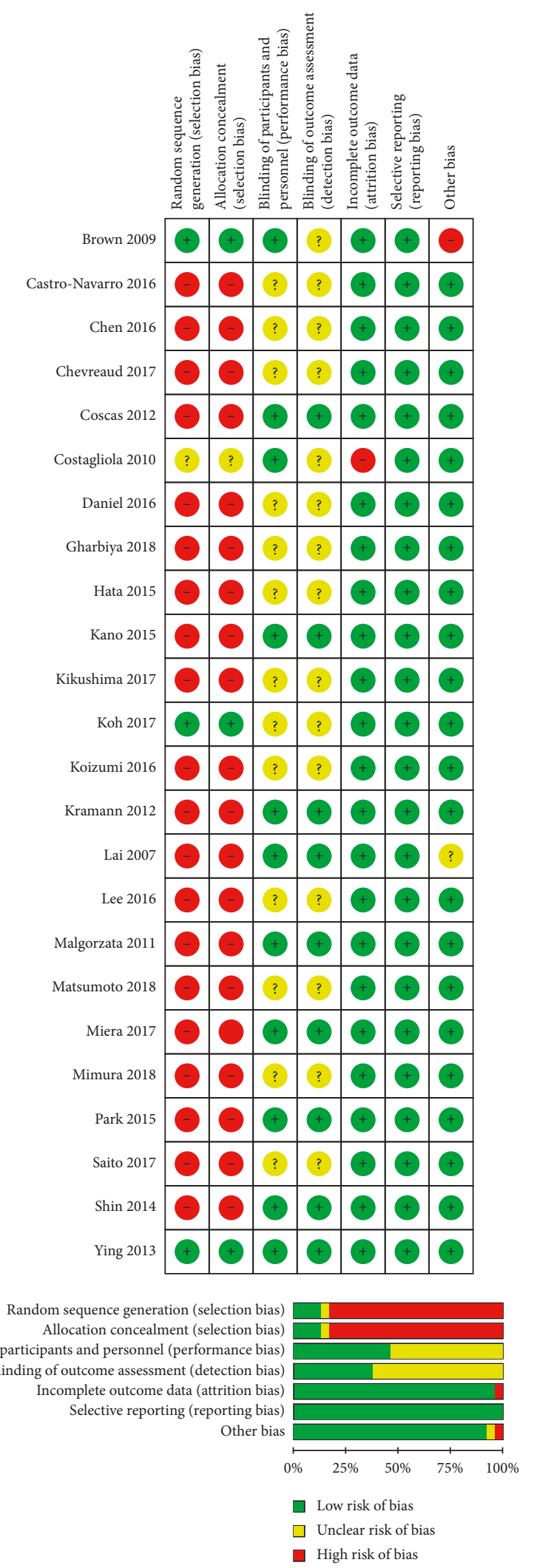

FIgURE 2: Risk of bias assessment of the included studies.

year, country where the study was conducted, subtype of nAMD, sample size, gender, mean age of the sample, vision criteria for recruitment, anti-VEGF use, and study design. 


\begin{tabular}{|c|c|c|c|c|c|c|}
\hline Study or subgroup & Mean difference & SE & Weight & $\begin{array}{l}\text { Mean difference } \\
\text { IV, random, 95\% CI }\end{array}$ & $\begin{array}{l}\text { Mean dif } \\
\mathrm{IV} \text {, random }\end{array}$ & $\begin{array}{l}\text { ifference } \\
m, 95 \% \mathrm{CI}\end{array}$ \\
\hline \multicolumn{7}{|l|}{ 1.1.1 Type 1} \\
\hline Chevreaud et al. [29] & -0.0532 & 0.0301 & $11.2 \%$ & $-0.05(-0.11,0.01)$ & -1 & \\
\hline Kano et al. [22] & -0.0667 & 0.0154 & $13.9 \%$ & $-0.07(-0.10,-0.04)$ & - & \\
\hline Kikushima et al. [30] & -0.11 & 0.0386 & $9.6 \%$ & $-0.11(-0.19,-0.03)$ & $\rightarrow$ & \\
\hline Koizumi et al. [27] & -0.1 & 0.0318 & $10.9 \%$ & $-0.10(-0.16,-0.04)$ & $-\square$ & \\
\hline Lee et al. [28] & -0.07 & 0.0871 & $3.8 \%$ & $-0.07(-0.24,0.10)$ & $=$ & - \\
\hline Mimura et al. [36] & -0.12 & 0.0069 & $14.9 \%$ & $-0.12(-0.13,-0.11)$ & - & \\
\hline Subtotal $(95 \% \mathrm{CI})$ & & & $64.2 \%$ & $-0.09(-0.12,-0.06)$ & 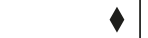 & \\
\hline \multicolumn{7}{|c|}{ Heterogeneity: $\tau^{2}=0.00 ; \chi^{2}=13.79, d f=5(P=0.02) ; I^{2}=64 \%$} \\
\hline \multicolumn{7}{|c|}{ Test for overall effect: $Z=5.76(P<0.00001)$} \\
\hline \multicolumn{7}{|l|}{ 1.1.2 Type 2} \\
\hline Chevreaud et al. [29] & 0.14 & 0.2041 & $0.9 \%$ & $0.14(-0.26,0.54)$ & & \\
\hline Lee et al. $[28]$ & -0.53 & 0.2306 & $0.7 \%$ & $-0.53(-0.98,-0.08)$ & & \\
\hline Malgorzata and Stankiewicz [16] & -0.19 & 0.054 & $7.1 \%$ & $-0.19(-0.30,-0.08)$ & & \\
\hline Subtotal $(95 \% \mathrm{CI})$ & & & $8.6 \%$ & $-0.18(-0.46,0.10)$ & & \\
\hline \multicolumn{7}{|c|}{ Heterogeneity: $\tau^{2}=0.04 ; \chi^{2}=4.78, d f=2(P=0.09) ; I^{2}=58 \%$} \\
\hline \multicolumn{7}{|c|}{ Test for overall effect: $Z=1.29(P=0.20)$} \\
\hline \multicolumn{7}{|l|}{ 1.1.3 Type 3} \\
\hline Chevreaud et al. [29] & -0.26 & 0.2216 & $0.7 \%$ & $-0.26(-0.69,0.17)$ & & \\
\hline Kramann et al. [18] & -0.22 & 0.0709 & $5.1 \%$ & $-0.22(-0.36,-0.08)$ & & \\
\hline Lai et al. [13] & -0.3 & 0.0431 & $8.8 \%$ & $-0.30(-0.38,-0.22)$ & - & \\
\hline Mimura et al. [36] & -0.19 & 0.0228 & $12.6 \%$ & $-0.19(-0.23,-0.15)$ & - & \\
\hline Subtotal $(95 \% \mathrm{CI})$ & & & $27.2 \%$ & $-0.23(-0.30,-0.16)$ & & \\
\hline \multicolumn{7}{|c|}{$\begin{array}{l}\text { Heterogeneity: } \tau^{2}=0.00 ; \chi^{2}=5.14, d f=3(P=0.16) ; I^{2}=42 \% \\
\text { Test for overall effect: } Z=6.81(P<0.00001)\end{array}$} \\
\hline Total $(95 \% \mathrm{CI})$ & & & $100.0 \%$ & $-0.14(-0.17,-0.10)$ & 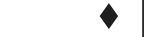 & \\
\hline Heterogeneity: $\tau^{2}=0.00 ; \chi^{2}=53.3$ & $f f=12(P<0.000$ & 1); $I^{2}=7$ & & & -0.5 & 0.5 \\
\hline
\end{tabular}

Test for overall effect: $Z=6.94(P<0.00001)$

Test for subgroup differences: $\chi^{2}=14.22, d f=2(P=0.0008) ; I^{2}=85.9 \%$

(a)

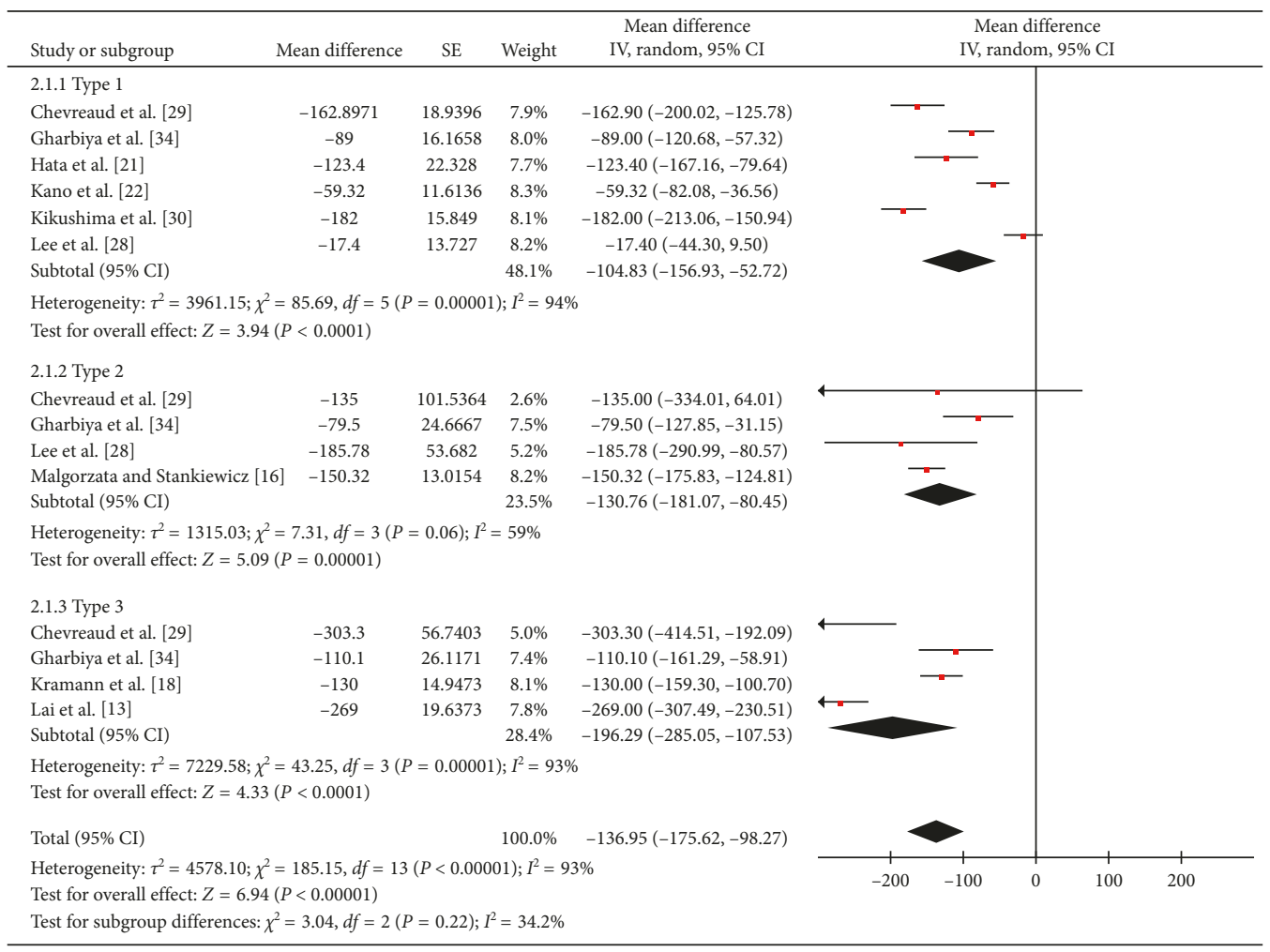

(b)

FIGURE 3: The short-term (3 months) efficacy comparison of antivascular endothelial growth factor (anti-VEGF) therapy for three subtypes of neovascular age-related macular degeneration (nAMD). (a) Vision improvement of the three types of nAMD, measured by logarithm of the minimum angle of resolution (logMAR), were -0.09 ( $95 \%$ confidence interval $(\mathrm{CI}):-0.12,-0.06),-0.18$ (95\% CI: $-0.46,0.10$ ), and -0.23 (95\% CI: $-0.30,-0.16)$. (b) Macular thickness decreases were -104.83 (95\% CI: $-156.93,-52.72),-130.76$ (95\% CI: $-181.07,-80.45)$, and -196.29 (95\% CI: $-285.05,-107.53) \mu \mathrm{m}$, respectively. 


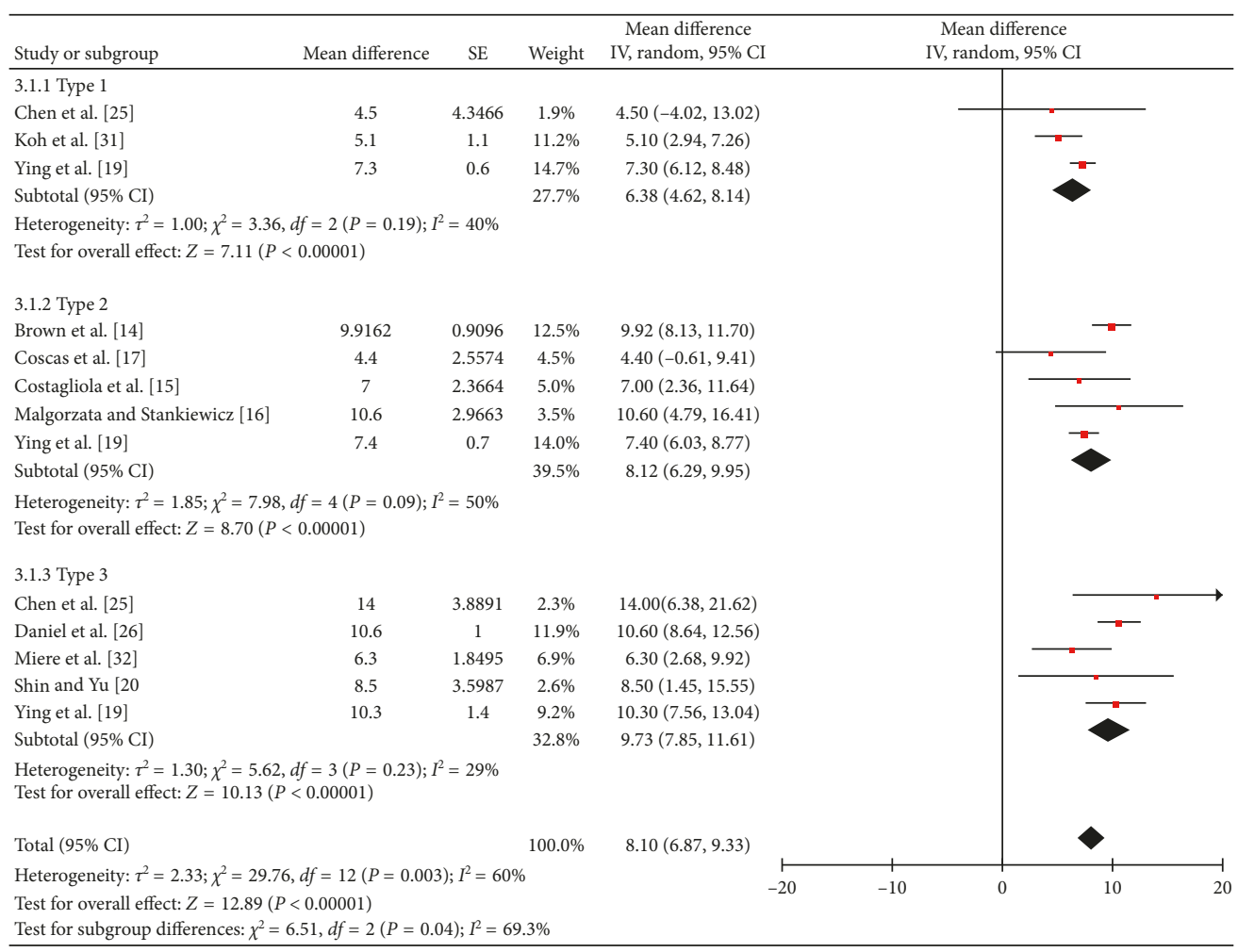

(a)

\begin{tabular}{|c|c|c|c|c|c|c|c|c|}
\hline \multirow{2}{*}{$\begin{array}{l}\text { Study or subgroup } \\
4.1 .1 \text { Type } 1\end{array}$} & \multirow[t]{2}{*}{ Mean difference } & \multirow[t]{2}{*}{ SE } & \multirow[t]{2}{*}{ Weight } & \multirow[t]{2}{*}{$\begin{array}{l}\text { Mean difference } \\
\text { IV, random, } 95 \% \mathrm{CI}\end{array}$} & \multicolumn{4}{|c|}{$\begin{array}{l}\text { Mean difference } \\
\text { IV, random, } 95 \% \mathrm{CI}\end{array}$} \\
\hline & & & & & & & & \\
\hline Chen et al. [25] & 3.1786 & 20.9835 & $7.0 \%$ & $-8.18(-49.31,32.95)$ & & & & \\
\hline Chevreaud et al. [29] & -167.5796 & 18.6932 & $7.4 \%$ & $-167.58(-204.22,-130.94)$ & & & & \\
\hline Kikushima et al. [30] & -161 & 15.9788 & $7.8 \%$ & $-161.00(-192.32,129.68)$ & & & & \\
\hline Matsumoto et al. [35] & -137 & 1.5706 & $9.0 \%$ & $-137.00(-140.08,-133.92)$ & & & & \\
\hline Saito et al. [33] & -154 & 25.6215 & $6.3 \%$ & $-154.00(-204.22,-103.78)$ & & & & \\
\hline Subtotal $(95 \% \mathrm{CI})$ & & & $37.5 \%$ & $-126.51(-167.58,-85.43)$ & & & & \\
\hline \multicolumn{9}{|c|}{ Heterogeneity: $\tau^{2}=1876.92 ; \chi^{2}=43.04, d f=4(P<0.00001) ; I^{2}=91 \%$} \\
\hline \multicolumn{9}{|c|}{ Test for overall effect: $Z=6.04(P<0.00001)$} \\
\hline \multicolumn{9}{|l|}{ 4.1.2 Type 2} \\
\hline Chevreaud et al. [29] & -31.7 & 93.1643 & $1.4 \%$ & $-31.70(-214.30,150.90)$ & & & & \\
\hline Coscas et al. [17] & -148.89 & 22.5067 & $6.8 \%$ & $-148.89(-193.00,-104.78)$ & & & & \\
\hline Costagliola et al. [15] & -107 & 13.1081 & $8.1 \%$ & $-107.00(-132.69,-81.31)$ & & & & \\
\hline Malgorzata and Stankiewicz [16] & -137.96 & 12.9258 & $8.2 \%$ & $-137.96(-163.29,-112.63)$ & & & & \\
\hline Subtotal $(95 \% \mathrm{CI})$ & & & $24.4 \%$ & $-126.52(-150.99,-102.05)$ & & & & \\
\hline \multicolumn{9}{|c|}{ Heterogeneity: $\tau^{2}=234.32 ; \chi^{2}=5.01, d f=3(P=0.17) ; I^{2}=40 \%$} \\
\hline \multicolumn{9}{|c|}{ Test for overall effect: $Z=10.13(P<0.00001)$} \\
\hline \multicolumn{9}{|l|}{ 4.1.3 Type 3} \\
\hline Castro-Navarro et al. [24] & -93.87 & 24.5405 & $6.5 \%$ & $-93.87(-141.97,-45.77)$ & & & & \\
\hline Chen et al. [25] & -113 & 34.6482 & $5.1 \%$ & $-113.00(-180.91,-45.09)$ & & & & \\
\hline Chevreaud et al. [29] & -285.6 & 59.7042 & $2.7 \%$ & $-285.60(-402.62,-168.58)$ & & & & \\
\hline Daniel et al. [26] & -240 & 17.8 & $7.5 \%$ & $-240.00(-274.89,-205.11)$ & & & & \\
\hline Park and Roh [23] & -88.11 & 13.9251 & $8.0 \%$ & $-88.11(-115.40,-60.82)$ & & & & \\
\hline Shin and Yu [20] & -68.4 & 12.1811 & $8.3 \%$ & $-68.40(-92.27,-44.53)$ & & & & \\
\hline Subtotal $(95 \% \mathrm{CI})$ & & & $38.0 \%$ & $-139.85,(-203.43,-76.28)$ & & & & \\
\hline \multicolumn{9}{|c|}{$\begin{array}{l}\text { Heterogeneity: } \tau^{2}=5484.53 ; \chi^{2}=76.46, d f=5(P<0.00001) ; I^{2}=93 \% \\
\text { Test for overall effect: } Z=4.31(P<0.0001)\end{array}$} \\
\hline Total $(95 \% \mathrm{CI})$ & & & $100.0 \%$ & $-128.31(-151.33,-105.29)$ & & & & \\
\hline \multicolumn{5}{|c|}{ Heterogeneity: $\tau^{2}=1523.21 ; \chi^{2}=136.11, d f=14(P<0.00001) ; I^{2}=90 \%$} & -200 & -100 & 100 & 200 \\
\hline Test for subgroup differences: $\chi^{2}=$ & $=0.15, d f=2(P=$ & $=0.93) ; I^{2}$ & $=0 \%$ & & & & & \\
\hline
\end{tabular}

(b)

FIGURE 4: The long-term (12 months) efficacy comparison among three subtypes of neovascular age-related macular degeneration (nAMD) was presented. (a) Vision improvement, evaluated by Early Treatment of Diabetic Retinopathy Study (ETDRS) letters, were 6.38 (95\% CI: 4.62, 8.14), 8.12 (95\% CI: 6.29, 9.95), and 9.73 (95\% CI: 7.85, 11.61) for the three types of nAMD. (b) Macular thickness changes were -126.51 (95\% CI: $-167.58,-85.43),-126.52$ (95\% CI: $-150.99,-102.05)$, and -139.85 (95\% CI: $-203.43,-76.28) \mu \mathrm{m}$, respectively. 


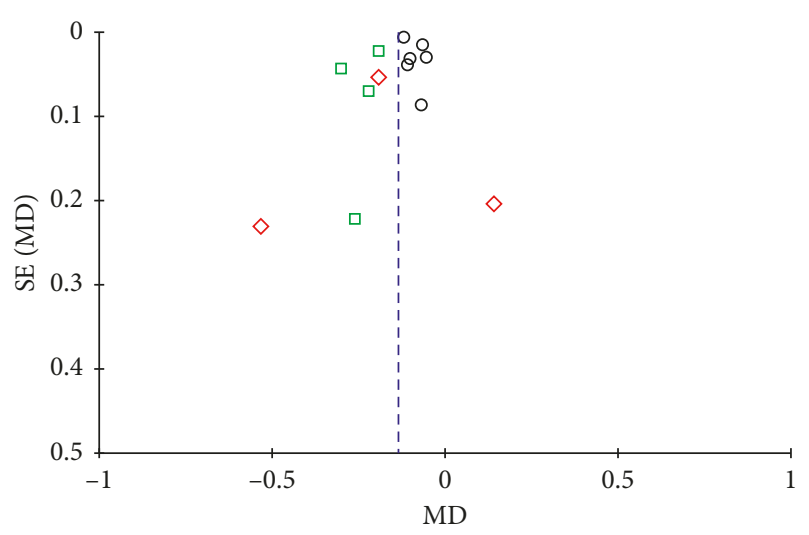

Subgroups

- Type 1

$\diamond$ Type 2

口 Type 3

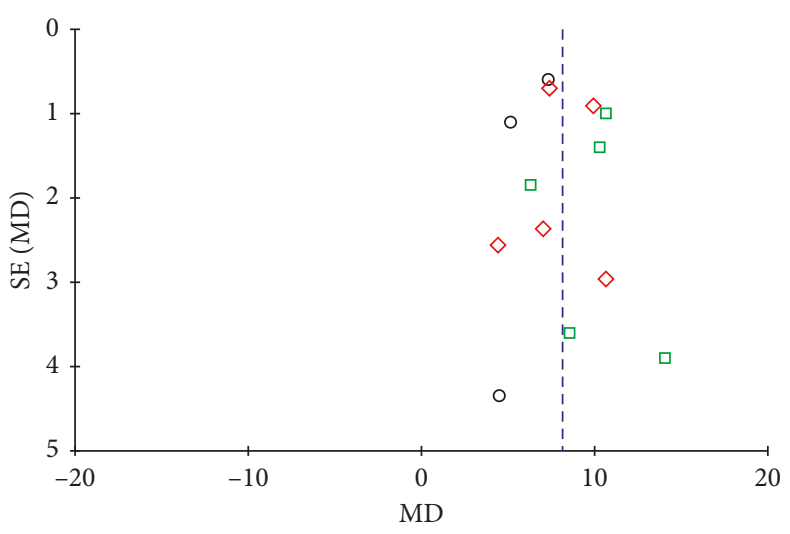
Subgroups
- Type 1
$\diamond$ Type 2
$\checkmark$ Type 3

(a)

(b)

FIGURE 5: Funnel plots for short-term (a) and long-term (b) vision improvement comparison.

Besides, PCV was marked in the column of subtype of nAMD in Table 1 since it was a variant of type 1 nAMD.

The main outcome of this meta-analysis was efficacy comparison of intravitreal anti-VEGF therapy for three subtypes of nAMD. The efficacy was measured by vision improvement or macular thickness (MT) changes at 3 or 12 months; therefore, these data were extracted for further analysis. Since meta-analysis was a second source, the relevant data were extracted either directly from the article or by extrapolation. In this study, no authors were contacted for the raw data of each patient, thus we could not adjust some different factors such as visual acuity at baseline.

2.5. Statistical Analysis. All the statistical analyses in our study were completed using Review Manager (RevMan) version 5.3 (The Nordic Cochrane Centre, Copenhagen, Denmark) and Stata version 12.0 (StataCorp, Texas, America). The effect value in this meta-analysis was the mean difference (MD). Before the analysis, the study heterogeneity was tested using both the I-squared and chi-squared test statistics. An $I^{2} \geq 50 \%$ and/or a $Q$-statistic of $p<0.05$ was evidence supporting the presence of heterogeneity, in which the random-effects modeling method was needed. Otherwise, the fixed-effects modeling method was applied. In addition, publication bias and sensitivity analysis were conducted to study the relevant bias as well as stability and reliability of the outcomes.

\section{Results}

3.1. Description of Studies. A total of 1147 articles were identified, and their records were included in EndNote X8 (Clarivate Analytics, Philadelphia, PA, US). After removing 242 duplicates, the remaining 905 articles were screened based on the titles and abstracts by two reviewers according to our inclusion criteria. Any disagreements about the inclusion of an article for full review were resolved by the third researcher. Full-text assessment was conducted on the rest of the 116 articles. Finally, 24 articles [13-36] were included in this meta-analysis. The article searches and selection process is summarized in Figure 1.

3.2. Study Quality and Characteristics. "Risk of bias" of these studies was assessed by "risk of bias table," and the outcome is summarized in Figure 2. The selection bias, which contained random sequence generation and allocation concealment, was mainly of high risk, predominantly due to those nonrandomized studies. Although blinding of performance and detection was not performed in most of the included studies, the outcome was not likely to be influenced by lack of blinding or there was insufficient information to permit judgement of "Low risk" or "High risk."

Among the included studies, 4 were randomized controlled trials (RCT), 12 were retrospective interventional studies (RIS), 6 were clinical trials, and the left 2 were case reports. Altogether, 2594 patients were involved in this review. The demographic characteristics of the studies were summarized in Table 1.

\subsection{Critical Appraisal Tool}

3.3.1. Short-Term Outcome. Figure 3 illustrated the shortterm (3 months) efficacy comparison. In Figure 3(a), vision improvements of the three types of nAMD, measured by logarithm of the minimum angle of resolution (logMAR), were -0.09 ( $95 \%$ confidence interval (CI): $-0.12,-0.06),-0.18$ (95\% CI: $-0.46,0.10)$, and -0.23 (95\% CI: $-0.30,-0.16$ ). While MT changes, displayed in Figure 3(b), were -104.83 (95\% CI: $-156.93,-52.72),-130.76$ (95\% CI: $-181.07,-80.45)$, and -196.29 (95\% CI: $-285.05,-107.53) \mu \mathrm{m}$, respectively. It was obvious that the efficacy varied among different subtypes of nAMD; however, the subtype difference was only statistically significant between type 1 and type 3 in vision improvement $(p=0.0002)$. 

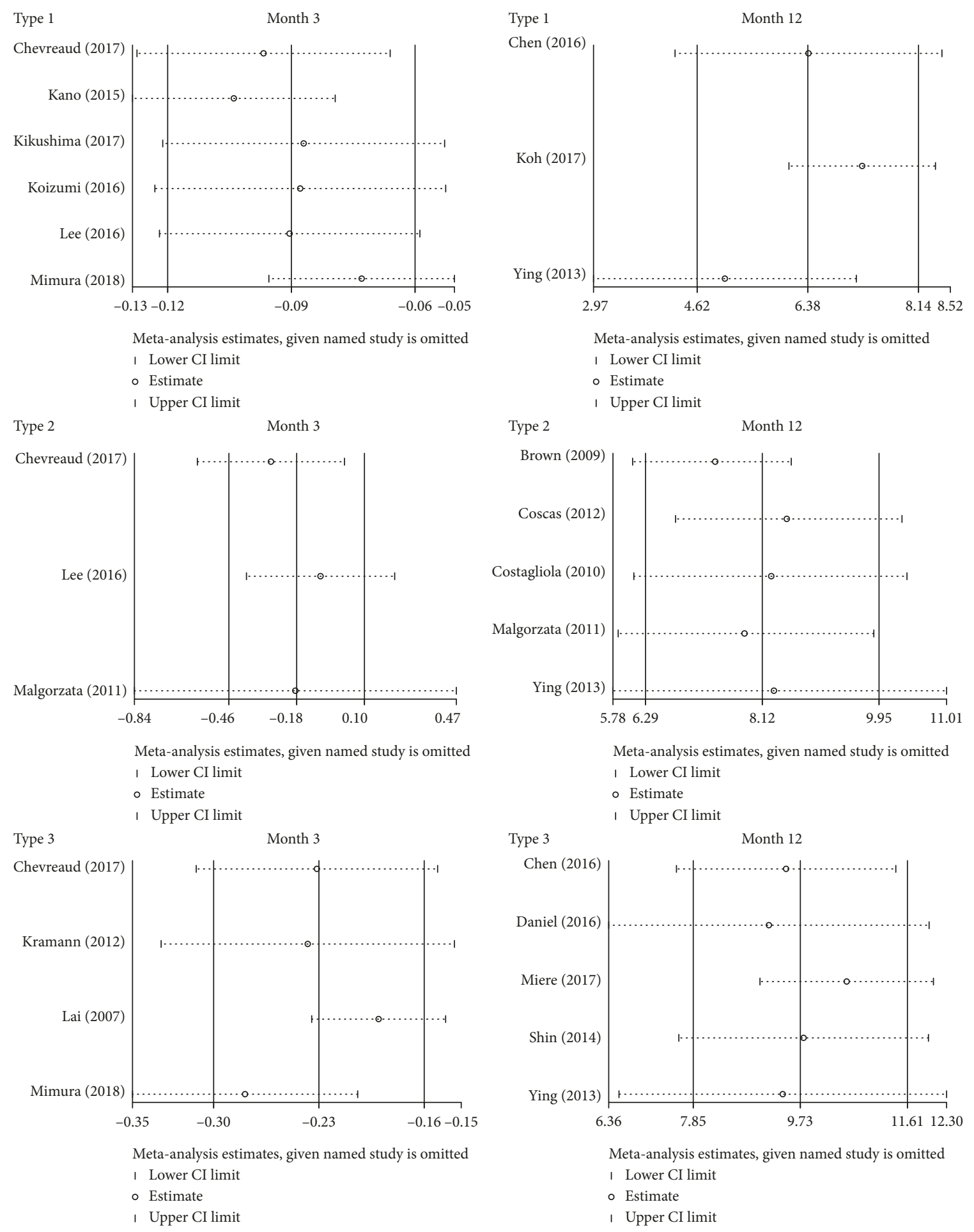

FIGURE 6: Sensitivity analysis on the outcome of vision improvement at 3 and 12 months.

3.3.2. Long-Term Outcome. The long-term (12 months) efficacy comparison was presented in Figure 4. Vision improvements, evaluated by Early Treatment of Diabetic Retinopathy Study (ETDRS) letters, were 6.38 (95\% CI: 4.62, 8.14), 8.12 (95\% CI: 6.29, 9.95), and 9.73 (95\% CI: 7.85, 11, 61) for the three types of nAMD. In Figure 4(b), MT changes were -126.51 (95\% CI: $-167.58,-85.43),-126.52$ (95\% CI: -150.99 , $-102.05)$, and -139.85 (95\% CI: $-203.43,-76.28) \mu \mathrm{m}$, respectively. Although the efficacy differed in the three types of nAMD, the statistically significant subtype difference still only existed between type 1 and type 3 in vision improvement $(p<0.0001)$.

3.4. Publication Bias. Funnel plots for short-term and longterm vision improvement comparison are shown in Figure 5. 
The two plots were both relatively symmetrical, which indicated little evidence of publication bias.

3.5. Sensitivity Analysis. The impact of individual data was examined for sensitivity analysis, which was conducted on the outcome of vision improvement at 3 and 12 months (Figure 6). When omitting each study, we found no obvious changes to the results, thus drawing a conclusion that our results on vision efficacy were stable and reliable.

\section{Discussion}

To our knowledge, this was the first meta-analysis quantitatively comparing treatment efficacy of intravitreal antiVEGF therapy for three subtypes of nAMD. A total of 24 articles were included in our systematic review. In order to assess the efficacy, the relevant data about vision improvement and MT changes at 3 months or 12 months were extracted for further pooled analysis. We found that although the efficacy of type 2 nAMD was superior to type 1 and inferior to type 3, statistically significant difference was only found between type 1 and 3 in vision improvement, both during the short term $(p=0.0002)$ and long term $(p=0.01)$. We could draw a conclusion that the reactivity to VEGF inhibitors varied among different subtypes of nAMD. Thus, the lesion subtype could be considered as a predictor for the treatment outcome.

There are several potential explanations for our results. First of all, the three types of nAMD are characterized with different locations of NV: sub-RPE, subretina, and intraretina. The closer to the retinal photoreceptors, the earlier and more severe the clinical symptoms of nAMD appear. Therefore, the three subtypes suffer from different durations and various severities. Another theory is anti-VEGF resistance, which means that tissues treated with anti-VEGF may develop resistance to hypoxia and become less dependent on angiogenesis or develop more mature vessels through remodeling, which is less responsive to antiangiogenic therapy [37]. Patients with type $1 \mathrm{nAMD}$ tend to agonize over longer duration, thus are more likely to develop anti-VEGF resistance. Therefore, treatment efficacy for type 1 is inferior to type 2 and 3.

So far, the three types of nAMD have been classified based on the location of abnormal vessels using fluorescence angiography (FA) and optical coherence tomography (OCT). Nevertheless, OCTA (and a possible OCTA classification) may offer additional information on treatment-response and anti-VEGF resistance by providing morphological information and quantitative measures (area, vascular density, fractal dimension, etc.), but that the clinical relevance of such findings is still debated [32, 38, 39].

Some limitations did exist in our systematic review. Firstly, this meta-analysis consisted mostly of nonrandomized studies which were more likely to be influenced by various kinds of biases. Hence, it was not surprising that almost all of them were at relatively high risk when we assessed the risk of bias as shown in Figure 2. However, there has been no way to control these biases and no method to assess their impact on the outcome so far. Secondly, heterogeneity was statistically significant across several results (Figures 3 and 4). One possible explanation was that nonrandomized studies were more likely to introduce heterogeneity due to confounding factors and all kinds of biases. Moreover, no authors were contacted for primary statistics. The relevant data were extracted either directly from the article or by extrapolation, thus we could not adjust some different factors at baseline. For example, of the 24 included studies, only 11 were involved with vision criteria for enrollment, and these criteria were various. However, we had no way to adjust visual acuity at baseline because of lacking individual patient data. Nevertheless, this problem might be a common limitation of meta-analysis.

\section{Conclusion}

In summary, we believe that this meta-analysis, comparing treatment efficacy among different types of $\mathrm{nAMD}$, is of great significance to clinical practice. The results indicate that lesion subtype is a predictor for the treatment outcome which could help guide prognosis.

\section{Conflicts of Interest}

The authors declare that they have no conflicts of interest.

\section{Authors' Contributions}

Jianqing Li and Peirong Lu designed the study and wrote the paper; Jianqing $\mathrm{Li}$ and Jiayi $\mathrm{Xu}$ searched the literature; Jianqing Li, Yiyi Chen, Jiaju Zhang, and Yihong Cao extracted and analyzed the data; Jianqing Li and Peirong Lu contributed to the improvement of the manuscript. All authors approved the submitted and final version.

\section{Acknowledgments}

This work was supported by the National Natural Science Foundation of China (NSFC No. 81671641), Jiangsu Provincial Medical Innovation Team (No. CXTDA2017039), Jiangsu Provincial Natural Science Foundation (No. BK20151208), and the Soochow Scholar Project of Soochow University (No. R5122001).

\section{References}

[1] L. S. Lim, P. Mitchell, J. M. Seddon, F. G. Holz, and T. Y. Wong, "Age-related macular degeneration," The Lancet, vol. 379, no. 9827, pp. 1728-1738, 2012.

[2] I. Bhutto and G. Lutty, "Understanding age-related macular degeneration (AMD): relationships between the photoreceptor/ retinal pigment epithelium/Bruch's membrane/choriocapillaris complex," Molecular Aspects of Medicine, vol. 33, no. 4, pp. 295-317, 2012.

[3] J. D. Gass, A. Agarwal, A. M. Lavina, and K. A. Tawansy, "Focal inner retinal hemorrhages in patients with drusen: an early sign of occult choroidal neovascularization and chorioretinal anastomosis," Retina, vol. 23, no. 6, pp. 741-751, 2003. 
[4] American Academy of Ophthalmology Retina/Vitreous Panel, Preferred Practice Pattern ${ }^{\circledR}$ Guidelines. Age-Related Macular Degeneration, American Academy of Ophthalmology, San Francisco, CA, USA, 2015, http://www.aao.org/ppp.

[5] Macular Photocoagulation Study Group, "Laser photocoagulation of subfoveal neovascular lesions in age-related macular degeneration. Results of a randomized clinical trial," Archives of Ophthalmology, vol. 109, no. 9, pp. 1220-1231, 1991.

[6] J. D. Gass, "Biomicroscopic and histopathologic considerations regarding the feasibility of surgical excision of subfoveal neovascular membranes," American Journal of Ophthalmology, vol. 118, no. 3, pp. 285-298, 1994.

[7] K. B. Freund, S. A. Zweifel, and M. Engelbert, "Do we need a new classification for choroidal neovascularization in agerelated macular degeneration?" Retina, vol. 30, no. 9, pp. 1333-1349, 2010.

[8] J. J. Jung, C. Y. Chen, S. Mrejen et al., "The incidence of neovascular subtypes in newly diagnosed neovascular agerelated macular degeneration," American Journal of Ophthalmology, vol. 158, no. 4, pp. 769-779.e2, 2014.

[9] H. Mehta, A. Tufail, V. Daien et al., "Real-world outcomes in patients with neovascular age-related macular degeneration treated with intravitreal vascular endothelial growth factor inhibitors," Progress in Retinal and Eye Research, vol. 64, pp. 127-146, 2018.

[10] H. Koizumi, M. Kano, A. Yamamoto et al., "Short-term changes in choroidal thickness after aflibercept therapy for neovascular age-related macular degeneration," American Journal of Ophthalmology, vol. 159, no. 4, pp. 627-633, 2015.

[11] B. Chae, J. J. Jung, S. Mrejen et al., "Baseline predictors for good versus poor visual outcomes in the treatment of neovascular age-related macular degeneration with intravitreal anti-VEGF therapy," Investigative Opthalmology \& Visual Science, vol. 56, no. 9, pp. 5040-5047, 2015.

[12] K. Hufendiek, K. Hufendiek, G. Panagakis, H. Helbig, and M. A. Gamulescu, "Visual and morphological outcomes of bevacizumab (Avastin ${ }^{\circledR}$ ) versus ranibizumab (Lucentis ${ }^{\circledR}$ ) treatment for retinal angiomatous proliferation," International Ophthalmology, vol. 32, no. 3, pp. 259-268, 2012.

[13] T. Y. Lai, W. M. Chan, D. T. Liu, and D. S. Lam, "Ranibizumab for retinal angiomatous proliferation in neovascular agerelated macular degeneration," Graefe's Archive for Clinical and Experimental Ophthalmology, vol. 245, no. 12, pp. 1877-1880, 2007.

[14] D. M. Brown, M. Michels, P. K. Kaiser et al., "Ranibizumab versus verteporfin photodynamic therapy for neovascular agerelated macular degeneration: two-year results of the ANCHOR study," Ophthalmology, vol. 116, no. 1, pp. 57-65.e5, 2009.

[15] C. Costagliola, M. R. Romano, M. Rinaldi et al., "Low fluence rate photodynamic therapy combined with intravitreal bevacizumab for neovascular age-related macular degeneration," British Journal of Ophthalmology, vol. 94, no. 2, pp. 180-184, 2010.

[16] F. Małgorzata and A. Stankiewicz, "Effectiveness of ranibizumab intravitreal injections for exudative age-related macular degeneration treatment: 12-month outcomes," Medical Science Monitor, vol. 17, no. 9, pp. CR485-CR490, 2011.

[17] F. Coscas, G. Querques, R. Forte, C. Terrada, G. Coscas, and E. H. Souied, "Combined fluorescein angiography and spectral-domain optical coherence tomography imaging of classic choroidal neovascularization secondary to age-related macular degeneration before and after intravitreal ranibizumab injections," Retina, vol. 32, no. 6, pp. 1069-1076, 2012.

[18] C. A. Kramann, K. Schöpfer, K. Lorenz, I. Zwiener, B. M. Stoffelns, and N. Pfeiffer, "Intravitreal ranibizumab treatment of retinal angiomatous proliferation," Acta Ophthalmologica, vol. 90, no. 5, pp. 487-491, 2012.

[19] G. S. Ying, J. Huang, M. G. Maguire et al., "Baseline predictors for one-year visual outcomes with ranibizumab or bevacizumab for neovascular age-related macular degeneration," Ophthalmology, vol. 120, no. 1, pp. 122-129, 2013.

[20] J. Y. Shin and H. G. Yu, "Optical coherence tomographybased ranibizumab monotherapy for retinal angiomatous proliferation in Korean patients," Retina, vol. 34, no. 12, pp. 2359-2366, 2014.

[21] M. Hata, A. Tsujikawa, M. Miyake et al., "Two-year visual outcome of ranibizumab in typical neovascular age-related macular degeneration and polypoidal choroidal vasculopathy," Graefe's Archive for Clinical and Experimental Ophthalmology, vol. 253, no. 2, pp. 221-227, 2015.

[22] M. Kano, T. Sekiryu, Y. Sugano et al., "Foveal structure during the induction phase of anti-vascular endothelial growth factor therapy for occult choroidal neovascularization in age-related macular degeneration," Clinical Ophthalmology, vol. 9, pp. 2049-2056, 2015.

[23] Y. G. Park and Y. J. Roh, "One year results of intravitreal ranibizumab monotherapy for retinal angiomatous proliferation: a comparative analysis based on disease stages," BMC Ophthalmology, vol. 15, no. 1, p. 182, 2015.

[24] V. Castro-Navarro, E. Cervera-Taulet, J. Montero-Hernández, and C. Navarro-Palop, "One-year outcomes of the treat-andextend approach with aflibercept in age-related macular degeneration: effects on typical choroidal neovascularization and retinal angiomatous proliferation," Ophthalmologica, vol. 236, no. 4, pp. 215-222, 2016.

[25] X. Chen, M. Al-Sheikh, C. K. Chan et al., "Type 1 versus type 3 neovascularization pigment epithelial detachments associated with age-related macular degeneration after anti-vascular endothelial growth factor therapy: a prospective Study," Retina, vol. 36, no. 1, pp. S50-S64, 2016.

[26] E. Daniel, J. Shaffer, G. S. Ying et al., "Outcomes in eyes with retinal angiomatous proliferation in the comparison of agerelated macular degeneration treatments trials (CATT)," Ophthalmology, vol. 123, no. 3, pp. 609-616, 2016.

[27] H. Koizumi, M. Kano, A. Yamamoto et al., "Subfoveal choroidal thickness during aflibercept therapy for neovascular age-related macular degeneration: twelve-month results," Ophthalmology, vol. 123, no. 3, pp. 617-624, 2016.

[28] J. Y. Lee, H. Chung, and H. C. Kim, "Changes in fundus autofluorescence after anti-vascular endothelial growth factor according to the type of choroidal neovascularization in agerelated macular degeneration," Korean Journal of Ophthalmology, vol. 30, no. 1, pp. 17-24, 2016.

[29] O. Chevreaud, H. Oubraham, S. Y. Cohen et al., "Ranibizumab for vascularized pigment epithelial detachment: 1-year anatomic and functional results," Graefe's Archive for Clinical and Experimental Ophthalmology, vol. 255, no. 4, pp. 743-751, 2017.

[30] W. Kikushima, Y. Sakurada, S. Yoneyama et al., "Incidence and risk factors of retreatment after three-monthly aflibercept therapy for exudative age-related macular degeneration," Scientific Reports, vol. 7, no. 1, p. 44020, 2017.

[31] A. Koh, T. Y. Y. Lai, K. Takahashi et al., "Efficacy and safety of ranibizumab with or without verteporfin photodynamic therapy for polypoidal choroidal vasculopathy: a randomized 
clinical trial," JAMA Ophthalmology, vol. 135, no. 11, pp. 1206-1213, 2017.

[32] A. Miere, G. Querques, O. Semoun et al., "Optical coherence tomography angiography changes in early type 3 neovascularization after anti-vascular endothelial growth factor treatment," Retina, vol. 37, no. 10, pp. 1873-1879, 2017.

[33] M. Saito, M. Kano, K. Itagaki, and T. Sekiryu, "Efficacy of intravitreal aflibercept in Japanese patients with exudative age-related macular degeneration," Japanese Journal of Ophthalmology, vol. 61, no. 1, pp. 74-83, 2017.

[34] M. Gharbiya, R. Giustolisi, J. Marchiori et al., "Comparison of short-term choroidal thickness and retinal morphological changes after intravitreal anti-VEGF therapy with ranibizumab or aflibercept in treatment-naive eyes," Current Eye Research, vol. 43, no. 3, pp. 391-396, 2018.

[35] H. Matsumoto, T. Hiroe, M. Morimoto, K. Mimura, A. Ito, and H. Akiyama, "Efficacy of treat-and-extend regimen with aflibercept for pachychoroid neovasculopathy and type 1 neovascular age-related macular degeneration," Japanese Journal of Ophthalmology, vol. 62, no. 2, pp. 144-150, 2018.

[36] K. Mimura, H. Matsumoto, M. Morimoto, and H. Akiyama, "Development of age-related macular degeneration (AMD) in the fellow eye of patients with AMD treated by treatand-extend intravitreal therapy with aflibercept," Ophthalmologica, vol. 239, no. 2-3, pp. 121-127, 2018.

[37] S. Yang, J. Zhao, and X. Sun, "Resistance to anti-VEGF therapy in neovascular age-related macular degeneration: a comprehensive review," Drug Design, Development and Therapy, vol. 10, pp. 1857-1867, 2016.

[38] D. Xu, J. P. Dávila, M. Rahimi et al., "Long-term progression of type 1 neovascularization in age-related macular degeneration using optical coherence tomography angiography," American Journal of Ophthalmology, vol. 187, pp. 10-20, 2018.

[39] A. Carnevali, M. V. Cicinelli, V. Capuano et al., "Optical coherence tomography angiography: a useful tool for diagnosis of treatment-naïve quiescent choroidal neovascularization," American Journal of Ophthalmology, vol. 169, pp. 189-198, 2016. 


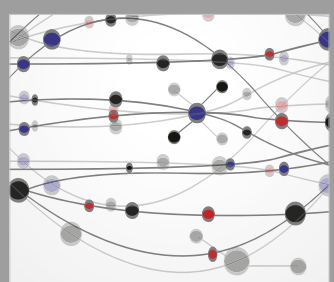

The Scientific World Journal
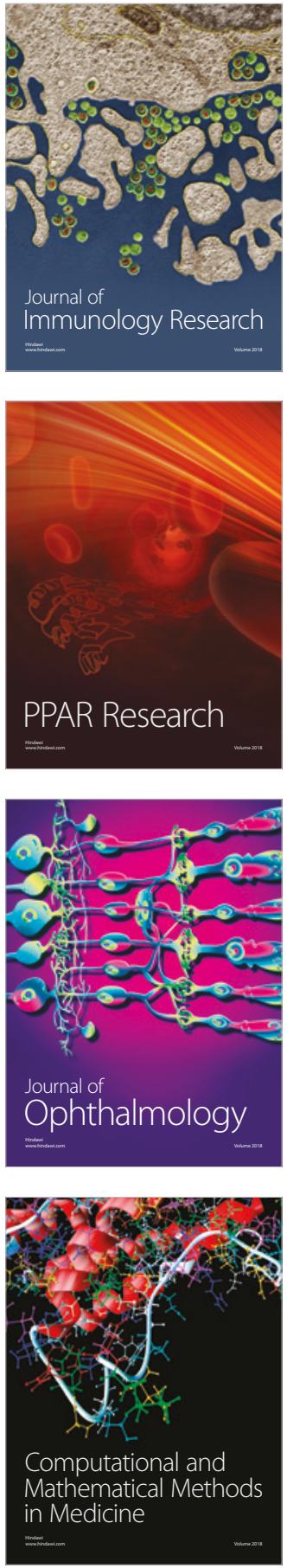

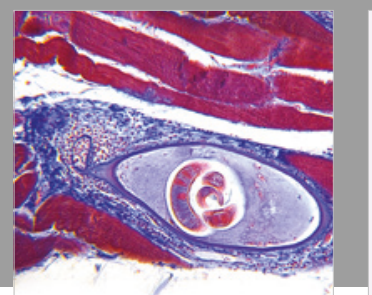

Gastroenterology Research and Practice

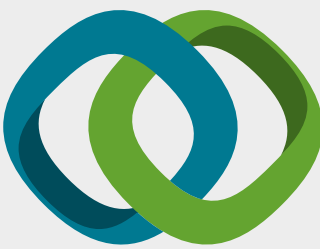

\section{Hindawi}

Submit your manuscripts at

www.hindawi.com
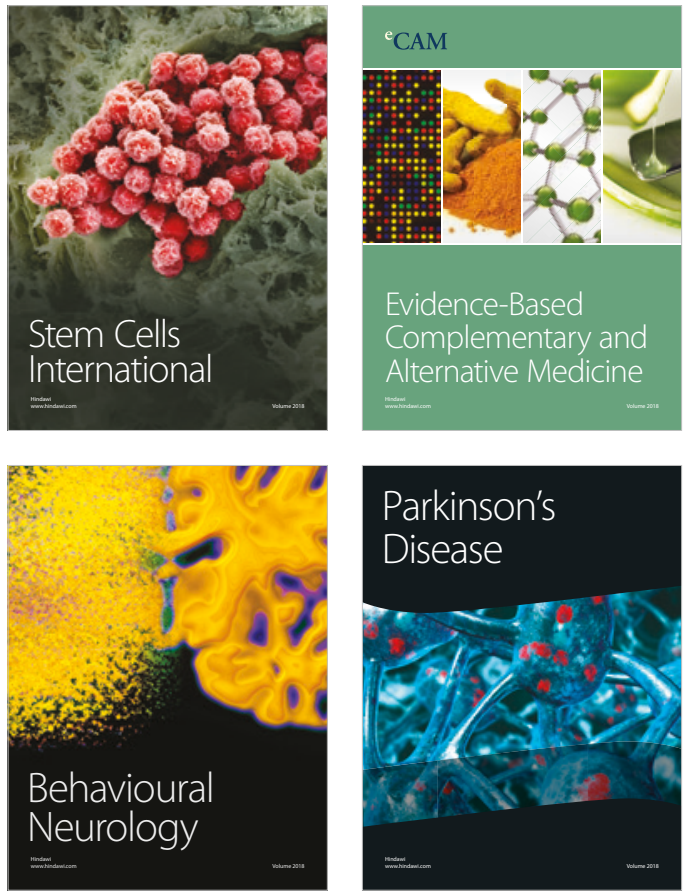

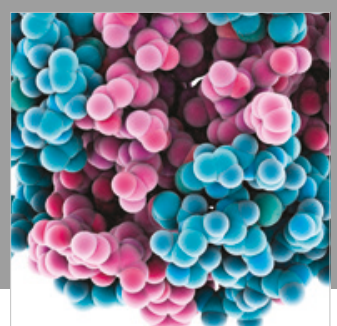

ournal of

Diabetes Research

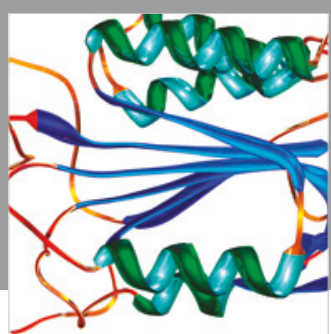

Disease Markers
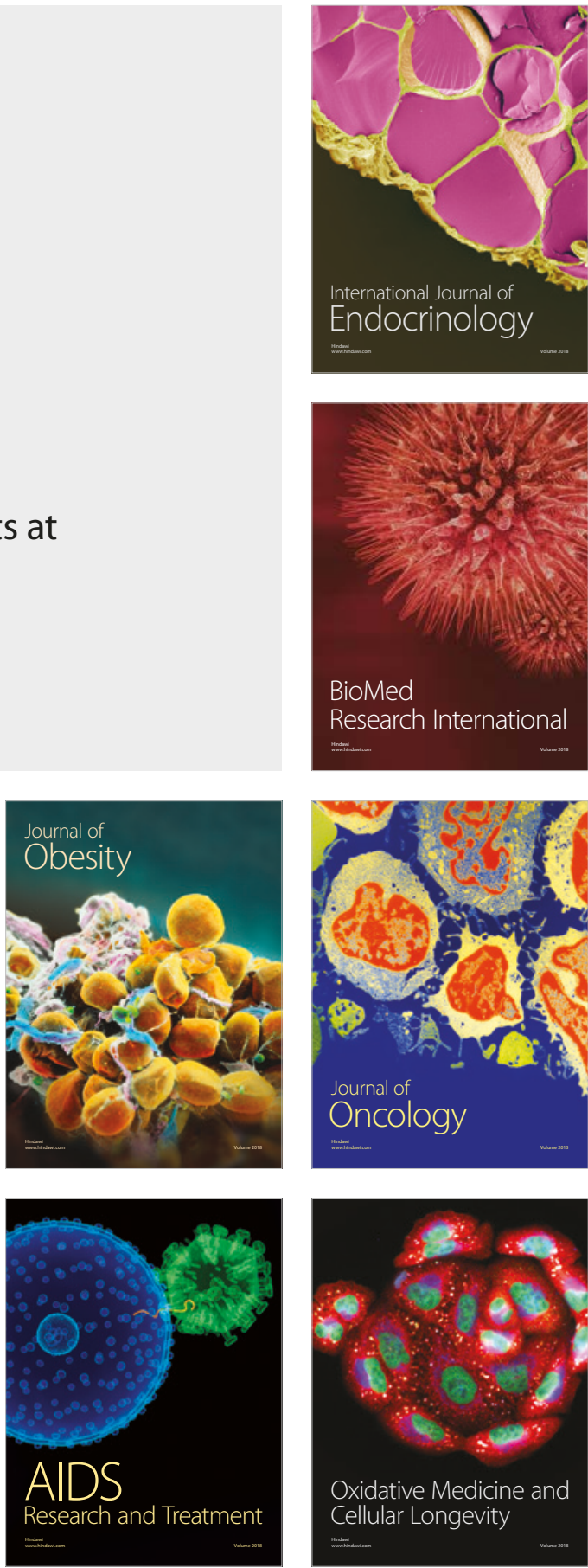